\title{
Adhesive bonding of resin composite to various titanium surfaces using different metal conditioners and a surface modification system
}

\author{
Hercules Jorge ALMILHATTI ${ }^{1}$, Karin Hermana NEPPELENBROEK ${ }^{2}$, Carlos Eduardo VERGANI ${ }^{3}$, Ana Lúcia MACHADO ${ }^{3}$, \\ Ana Cláudia PAVARINA3 ${ }^{3}$, Eunice Teresinha GIAMPAOLO ${ }^{3}$
}

\author{
1- Department of Restorative Dentistry, Federal University of Paraná - UFPR, Curitiba, PR, Brazil. \\ 2- Department of Prosthodontics, Bauru School of Dentistry, University of São Paulo, Bauru, SP, Brazil. \\ 3- Department of Dental Materials and Prosthodontics, Araraquara Dental School, Univ. Estadual Paulista - UNESP, Araraquara, SP, Brazil.
}

Corresponding address: Hercules Jorge Almilhatti - Departamento de Odontologia Restauradora - Universidade Federal do Paraná - UFPR - Av. Pref. Lothário Meissner, 632 - Curitiba - PR - Brasil - 80210-170 - Phone: +55 4133604038 - Fax: +55 4133604052 - e-mail: almilhatti@yahoo.com.br

Submitted: April 11, 2013 - Modification: September 10, 2013 - Accepted: November 7, 2013

$\mathrm{O}$ bjective: This study evaluated the effect of three metal conditioners on the shear bond strength (SBS) of a prosthetic composite material to cPTi grade I having three surface treatments. Material and Methods: One hundred sixty eight rivet-shaped specimens $(8.0 \times 2.0 \mathrm{~mm})$ were cast and subjected to polishing $(\mathrm{P})$ or sandblasting with either $50 \mu \mathrm{m}$ (50SB) or $250 \mu \mathrm{m}$ (250SB) $\mathrm{Al}_{2} \mathrm{O}_{3}$. The metal conditioners Metal Photo Primer (MPP), Cesead II Opaque Primer (OP), Targis Link (TL), and one surface modification system Siloc (S), were applied to the specimen surfaces, which were covered with four 1-mm thick layers of resin composite. The resin layers were exposed to curing light for $90 \mathrm{~s}$ separately. Seven specimens from each experimental group were stored in water at $37^{\circ} \mathrm{C}$ for $24 \mathrm{~h}$ while the other 7 specimens were subjected to 5,000 thermal cycles consisting of water baths at $4^{\circ} \mathrm{C}$ and $60^{\circ} \mathrm{C}(\mathrm{n}=7)$. All specimens were subjected to SBS test $(0.5 \mathrm{~mm} / \mathrm{min})$ until failure occurred, and further 28 specimens were analyzed using scanning electron microscope (SEM) and X-ray energy-dispersive spectroscopy (EDS). Data were analyzed by 3-way ANOVA followed by post-hoc Tukey's test $(\alpha=0.05)$. Results: On 50SB surfaces, OP groups showed higher SBS means than MPP $(P<0.05)$, while no significant difference was found among OP, S, and TL groups. On 250SB surfaces, OP and TL groups exhibited higher SBS than MPP and $S(P<0.05)$. No significant difference in SBS was found between OP and TL groups nor between MPP and S groups. The use of conditioners on 250SB surfaces resulted in higher SBS means than the use of the same products on 50SB surfaces $(P<0.05)$. Conclusion: Sandblasting associated with the use of metal conditioners improves SBS of resin composites to $\mathrm{cpTi}$.

Key words: Dental materials. Dental alloys. Composite resins. Dental prosthesis.

\section{INTRODUCTION}

The use of titanium for dental implants and metal ceramic restorations, such as cast restorations or partial dentures, has increased over the last years because of their biocompatibility and optimum mechanical properties $6,9,23,29$. However, low bond strengths between titanium and composite veneering systems have been reported $3,11,20,21,29,32$. To overcome this limitation, several methods have been proposed to maximize the bonding of resin composite to titanium. Such methods are based on macro- and micromechanical retention, chemical bonding, or a combination of both mechanisms ${ }^{6,9}$.

The first bonding technique was the Silicoater system, introduced in 1984 as a "system of molecular bond" between resins and metal alloy surfaces ${ }^{34}$. In that system, the bonding mechanism consists of a heat fusion of a microscopic layer of silica to the metal by the so-called silica coating method, and the composite is bonded to the metal surface with a silane coupling agent in a process known as pyrolytic 
silanization $5,34,35$

New bonding systems that combine adhesive resins with chemically active monomers capable of bonding directly to sandblasted alloy surfaces have also been developed $15,16,17$. When these new adhesive systems are used along with conditioning methods, only sandblasting of the metal surface is required for these bonding agents to provide reliable bond strength between the resin composite and metal surface ${ }^{14}$. The bonding agents lead to some mechanism of chemical bonding with different alloys, so the micromechanical retention created by sandblasting increases considerably ${ }^{28}$. Phosphoric acid and carboxylic acid functional monomers used in most adhesive opaque resins and promoters are effective to bond resin composites to base metal alloys. For this reason, with the use of an appropriate adhesive metal primer, no surface preparations such as boxes, grooves, or retentive pearls are required on the metal frameworks prior to the application of light-cured veneering resins ${ }^{38}$.

Now, several adhesive primers containing different functional monomers to bond resin to base metals are commercially available ${ }^{2}$. However, the effects of these products on the bond strength of metals to resin have not yet been evaluated. Such an issue deserves more concern when the bonding between resin composite and titanium surface with metal primers are subjected to all the stresses created in vivo. In this regard, the combination between water storage and thermal cycling reproduces the in vivo conditions more accurately $7,8,12,22$, providing evidence of the long-term effectiveness of metal primers on bond strength of resin composites to titanium surfaces.

Therefore, the purpose of this study was to evaluate whether surface pre-treatment of commercially pure titanium grade I (cpTi) with sandblasting associated with three metal conditioners or with one surface modification system would improve the bond strength of a light-activated resin composite to the base metal after thermocycling. The tested hypotheses were: (1) metal primers provide similar increase in shear bond strength (SBS); (2) and SBS values between resin and metal surfaces treated with metal primers are not impaired by thermal cycling.

\section{MATERIAL AND METHODS}

The materials used in this study are given in Figure 1. A total of 196 rivet-shaped specimens (8.0 x $2.0 \mathrm{~mm}$ ) were cast with cpTi (Tritan $\AA$, Dentaurum J. P. Winkelstroeter KG, Pforzheim, Germany) using electric plasma arc in an inert gas-conditioned casting machine (EDG Equipments, São Carlos, SP, Brazil) ${ }^{1}$ according to the manufacturer's instructions. After casting, the disk surfaces were gradually polished with up to 600-grit silicon-carbide papers under constant cooling water. The metal specimens were then washed with isopropyl alcohol for $10 \mathrm{~min}$ with ultrasonic agitation.

\section{Experimental design}

The study design is illustrated in Figure 2. The specimens were assigned to 3 groups, and were submitted to 3 surface treatments: (1) polishing control with 600-grit silicon-carbide paper (P), (2) Sandblasting with either $50 \mu \mathrm{m} \mathrm{Al}_{2} \mathrm{O}_{3}$ (50SB) or (3) $250 \mu \mathrm{m} \mathrm{Al}_{2} \mathrm{O}_{3}$ (250SB). Sandblasting was performed perpendicularly to the metal surface at a distance of $5 \mathrm{~mm}$ and at $0.5 \mathrm{MPa}$ for $15 \mathrm{~s}$ (Basic Classic; Renfert GmbH, Hilzingen, Germany) 37,39 .

After surface preparation was completed, each group (56 specimens) was divided into four subgroups, according to the metal conditioners and metal surface modification system applied to the disk surfaces. In addition, 14 specimens from the 50SB group and 14 specimens from the 250SB group were

\begin{tabular}{|c|c|c|c|c|}
\hline Material & Identification & Abbreviation & Manufacturer & Component \\
\hline Metal & Tritan & cp Ti grade I & Dentaurum, Germany & $\mathrm{Ti}^{3} 99.5 \%$, others $0.5 \%$ \\
\hline \multirow[t]{3}{*}{ Metal conditioners } & Metal Photo Primer & MPP & Shofu, Kyoto, Japan & $\begin{array}{l}\text { 4-acryloyloxyethyl } \\
\text { trimellitate }\end{array}$ \\
\hline & Targis link & $\mathrm{TL}$ & Ivoclar, Liechtenstein & $\begin{array}{l}\text { 10-methacryloyloxydecyl } \\
\text { dihydrogen phosphate }\end{array}$ \\
\hline & $\begin{array}{c}\text { Cesead II Opaque } \\
\text { Primer }\end{array}$ & OP & Kuraray, Osaka, Japan & $\begin{array}{l}\text { 10-methacryloyloxydecyl } \\
\text { dihydrogen phosphate }\end{array}$ \\
\hline $\begin{array}{c}\text { Metal surface } \\
\text { modification system }\end{array}$ & Siloc Bonding System & $S$ & $\begin{array}{c}\text { Heraeus Kulzer, } \\
\text { Wehrheim, Germany }\end{array}$ & $\begin{array}{l}\text { Methacryloxypropl } \\
\text { trimethoxysilane }\end{array}$ \\
\hline Opaque resin & C \& B Opaque & $\mathrm{O}$ & $\begin{array}{c}\text { Heraeus Kulzer, } \\
\text { Wehrheim, Germany }\end{array}$ & Opaque OA3 \\
\hline $\begin{array}{c}\text { Composite veneering } \\
\text { material }\end{array}$ & Artglass & A & $\begin{array}{c}\text { Heraeus Kulzer, } \\
\text { Wehrheim, Germany }\end{array}$ & Dentin A3 \\
\hline
\end{tabular}

Figure 1- Materials used in this study 
left untreated to receive only opaque and dentin resins (control groups - OD).

The following metal conditioners were applied to the metal surfaces: MPP (Metal Photo Primer, Shofu Inc., Kyoto, Japan), OP (Cesead II Opaque Primer, Kuraray Co. Ltd., Osaka, Japan), S (Siloc Bonding System, Heraeus-Kulzer $\mathrm{GmbH}$, Wehrheim, Germany) - a metal surface modification system, and TL (Targis link, Ivoclar Vivadent, Schaan, Liechtenstein) (Figure 3). When the metal conditioner was presented as a single bottle product, the product was brushed directly on the alloy surface, according to the manufacturers' instructions. For the Siloc Bonding System, one coat of primer (Siloc Pre, Heraeus-Kulzer GmbH, Wehrheim, Germany) was applied to the specimen surfaces with a single brush application. The primed specimens were allowed to dry for 2 min and were placed in an activation chamber (Silicoater MD, Heraeus-Kulzer, Wehrheim, Germany), as recommended by the manufacturer. At the end of the cycle, the specimens were removed from the oven and were left at room temperature for 4 min.

Afterward, one coat of the bonding agent (Siloc Bond, Heraeus-Kulzer, Wehrheim, Germany) was applied with a single brush and was allowed to dry for $5 \mathrm{~min}$. Two $1-\mathrm{mm}$ thick layers of an opaque resin (O) were applied to the metal surfaces and each layer was exposed to light for $90 \mathrm{~s}$ in a laboratory light-curing unit (Dentacolor XS, Heraeus-Kulzer, Wehrheim, Germany), according to the manufacturers' recommendation. A cylindrical stainless steel split mold having an internal hole having $8 \mathrm{~mm}$ of diameter and being 2-mm thick was positioned on the specimen and two 1-mm-thick layers of dentin composite $(A)$ were inserted into the mold. The mold was removed and each layer was then exposed to light for $90 \mathrm{~s}$ using the same light-curing unit, resulting in a total light exposure of $180 \mathrm{~s}$.

Seven specimens from each experimental group $(n=7)$ were stored in distilled water at $37^{\circ} \mathrm{C}$ for 24 h (TO), while the other 7 specimens were stored in distilled water at $37^{\circ} \mathrm{C}$ for $24 \mathrm{~h}$ followed by 5,000 thermal cycles (T1), which consisted of water baths at $4^{\circ} \mathrm{C}$ and $60^{\circ} \mathrm{C}$ with a dwell time of $15 \mathrm{~s}$ in each bath (MSCT-3 Plus; Marcelo Nucci - ME; São Carlos, $\mathrm{SP}$, Brazil). All specimens were then subjected to an SBS test using a machine of mechanical test MTS 810 (Material Test System Corporation, Minneapolis, MN, USA) at a crosshead speed of $0.5 \mathrm{~mm} / \mathrm{min}$ until failure occurred ${ }^{21,30}$. The SBS values were obtained in Kgf and converted into megapascals ( $\mathrm{MPa}$ ).

Fractured surfaces were evaluated with an optical stereomicroscope (Carl Zeiss Jena $\mathrm{GmbH}$, Jena, Germany) at 40x magnification to determine the failure pattern, which was classified as follows: cohesive, when the fracture was located within the resin composite; adhesive, when the fracture was located between the resin composite and metal surface; or mixed, when the fracture was located within the resin composite and between the resin composite and metal surface. In addition, a representative specimen surface of each experimental group was evaluated with a scanning electron microscope (SEM) operating at $20 \mathrm{kV}$ (JSM-T33AO, JEOL Ltd., Tokyo, Japan), before and after particle abrasion. All representative specimen surfaces were also examined by X-ray energy-dispersive spectroscopy - EDS (JSM-T33AO, JEOL Ltd., Tokyo, Japan) at $20 \mathrm{kV}$ and live time of $100 \mathrm{~s}$.

Levene and Shapiro-Wilk tests (Statistica 6.0, Statsoft Inc., Tulsa, OK, USA) were applied to evaluate the homogeneity and normality among SBS means $(P>0.05)$ respectively. The SBS means were submitted to 3-way ANOVA (surface treatment, conditioner, and thermocycling) at a 95\% confidence level. One-way ANOVA (Statistica 6.0, Statsoft Inc., Tulsa, OK, USA) was performed to compare the differences in SBS means of groups having different conditioners only within the group with polished surfaces $(P)$. Differences among means were determined by post-hoc Tukey's test at a preset alpha of $5 \%$. The OD group was not included in the statistical tests because this group was only added to the study to provide the SBS values when no conditioners are used.

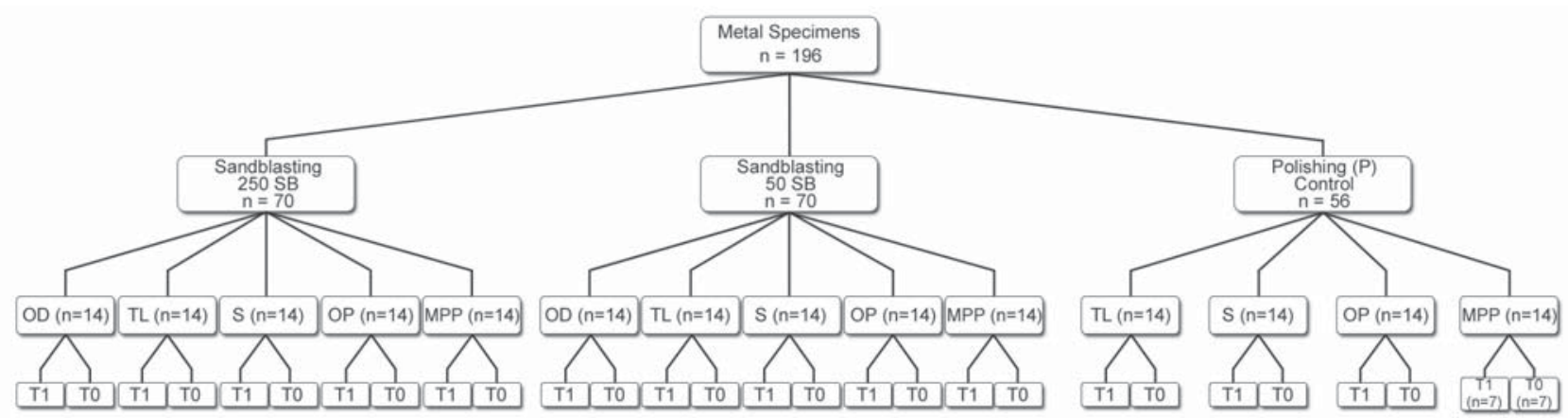

Figure 2- Flowchart of the experimental design 

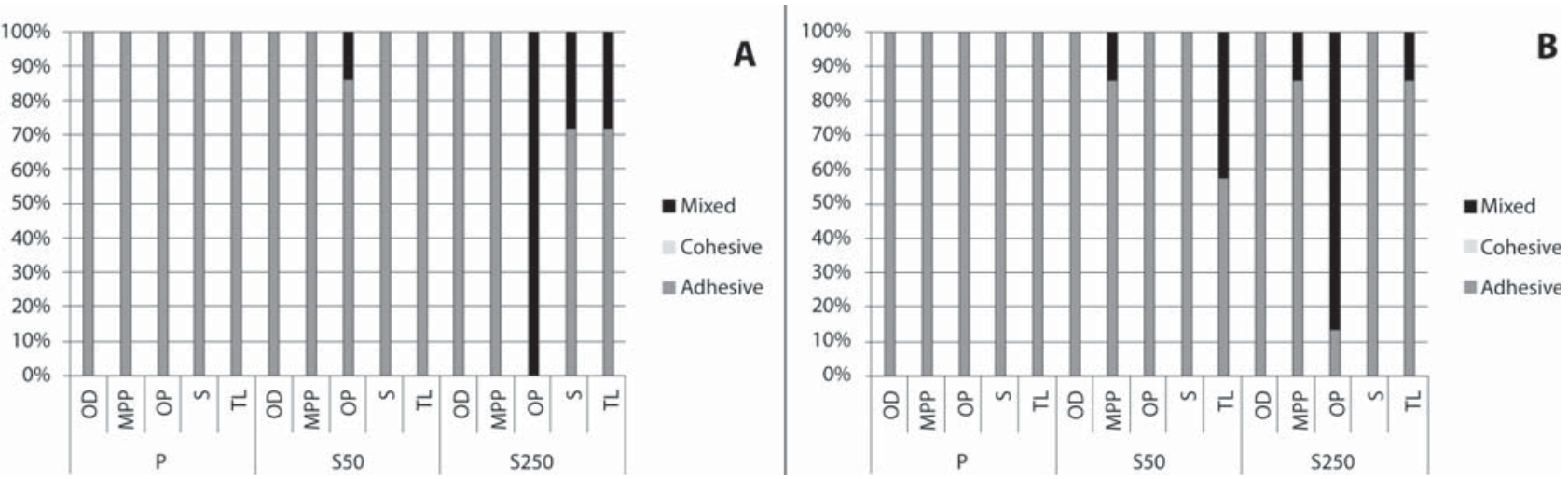

Figure 3- Failure patterns of all experimental groups at T0 (A) and T1 (B)

Table 1- Shear bond strength (MPa) mean values ( \pm standard deviations) of resin composite to sandblasted cpTi surfaces with metal primers. Means followed by the same capital letters in a column and lower case on the lines do not differ significantly by the Tukey test $(\alpha=0.05)$

\begin{tabular}{ccc}
\hline Metal primers & \multicolumn{2}{c}{ Sandblasting } \\
& 50SB & 250SB \\
\hline MPP & $6.7(0.9)^{\mathrm{Bb}}$ & $9.8(1.4)^{\mathrm{Ba}}$ \\
\hline OP & $9.3(2.1)^{\mathrm{Ab}}$ & $13.2(2.0)^{\mathrm{Aa}}$ \\
$\mathrm{S}$ & $8.5(1.2)^{\mathrm{ABa}}$ & $10.2(0.9)^{\mathrm{Ba}}$ \\
\hline $\mathrm{TL}$ & $8.4(1.2)^{\mathrm{ABb}}$ & $12.4(2.0)^{\mathrm{Aa}}$ \\
\hline
\end{tabular}

\section{RESULTS}

Forty-two thermocycled specimens without any treatment agent showed premature adhesive failures prior to the mechanical testing and were excluded from the study. The 3-way ANOVA detected a significant interaction between "treatment" and "conditioner" factors as well as between "thermocycling" and "conditioner" $(P<0.05)$. Within the 50SB group, the SBS values of OP (9.3 MPa) were only higher than those of MPP (6.7 MPa) $(P<0.05)$, while no significant difference was noted between OP, $\mathrm{S}$, and TL (Table 1). Within the 250SB group, OP (13.2 MPa) and TL (12.4 MPa) showed significantly higher SBS means than MPP (9.8 MPa) and $S(10.2 \mathrm{MPa})(P<0.05)$, while no significant difference was noted neither between OP and TL nor between MPP and S (Table 1 ). Overall, the SBS means of most 250SB groups with surface conditioners were higher than those of 50SB $(P<0.05)$. The only exception was observed when $\mathrm{S}$ was used, as no significant difference in SBS was noted between 50SB and 250SB groups (from 6.6 $\mathrm{MPa}$ to 9.7 $\mathrm{MPa}, P>0.05)$.

No significant difference in SBS means was observed between T0 and T1 $(P>0.05)$. At T0, no significant difference in the SBS values was observed between TL (10.6 MPa) and OP (10.4 MPa), or between MPP (8.4 MPa) and S (9.6 MPa) $(P>0.05)$
Table 2- Shear bond strength ( $\mathrm{MPa}$ ) mean values ( \pm standard deviations) of resin composite to sandblasted $\mathrm{cpTi}$ surfaces with metal primers after $24 \mathrm{~h}$ of water storage (T0) or after thermocycling (T1). Means followed by the same capital letters in a column and lower case on the lines do not differ significantly by the Tukey test $(\alpha=0.05)$

\begin{tabular}{ccc}
\hline Metal primers & \multicolumn{2}{c}{ Storage condition } \\
& T0 & T1 \\
\hline MPP & $8.4(1.3)^{\mathrm{Ba}}$ & $8.1(1.0)^{\mathrm{Ba}}$ \\
OP & $10.4(2.2)^{\mathrm{Aa}}$ & $12.1(1.9)^{\mathrm{Aa}}$ \\
S & $9.6(1.2)^{\mathrm{Ba}}$ & $9.1(0.9)^{\mathrm{Ba}}$ \\
TL & $10.6(1.9)^{\mathrm{Aa}}$ & $10.2(1.4)^{\mathrm{Ba}}$ \\
\hline
\end{tabular}

(Table 2). The SBS means of OP and TL were higher than those of MPP $(P<0.05)$. At T1, OP $(12.1 \mathrm{MPa})$ showed higher SBS values than MPP (8.1 MPa), S (9.1 $\mathrm{MPa})$, and TL (10.2 MPa) $(P<0.05)$ (Table 2). One-way ANOVA (Table 2) indicated no significant differences in SBS among groups with conditioners $(P>0.05)$.

At T0 and T1 (Figure 3), debonded surfaces from most groups showed $100 \%$ adhesive failures located between the metal surface and opaque resin. At T0, only the OP/S250 group exhibited $100 \%$ of mixed failures, while OP/50SB (14\%), S/250SB (28\%), and TL/250SB (28\%) showed small amounts of mixed failures. A similar pattern was observed at $\mathrm{T} 1$, but a small increase in mixed failures (14\%) was observed in MPP/250SB and TL/50SB groups in comparison to the failure patterns at TO. In contrast to the failure pattern of the S/250SB group at T0, the S/250SB group at T1 showed a $100 \%$ adhesive failure pattern. The effect of sandblasting on the surface morphology and composition of specimens from groups $P, 50 S B$, and 250SB can be seen on SEM micrographs and EDS spectra (Figures 4, 5, and 6). It is possible to note the effects of varying sizes of aluminum oxide on surface morphology (Figures $5 A$ and $6 A$ ), since pressure, time of sandblasting, and distance from the metal 

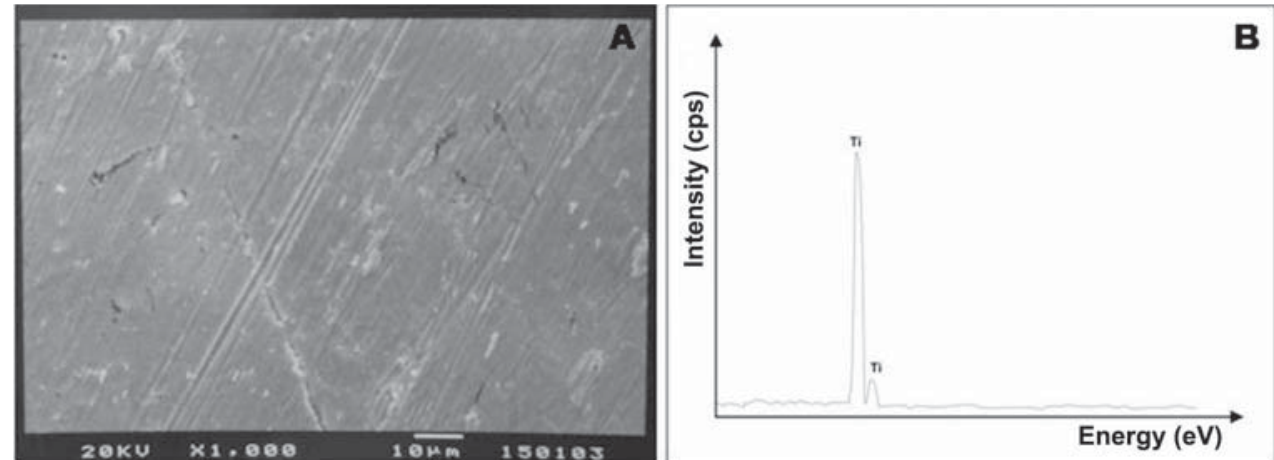

Figure 4- Scanning electron microscopy analysis for cpTi before sandblasting
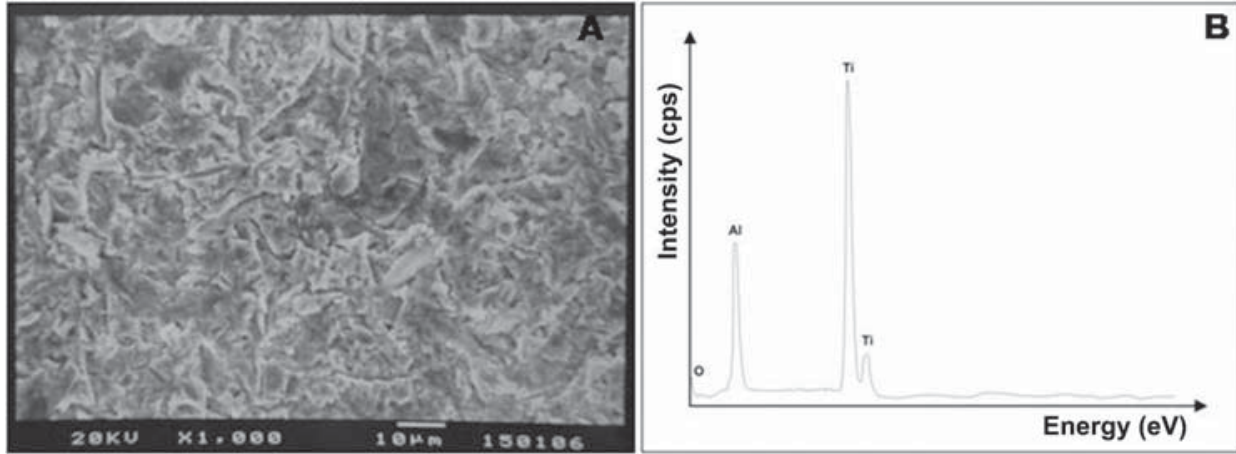

Figure 5- Scanning electron microscopy analysis for cpTi after sandblasting with $50 \mu \mathrm{m} \mathrm{Al}_{2} \mathrm{O}_{3}$
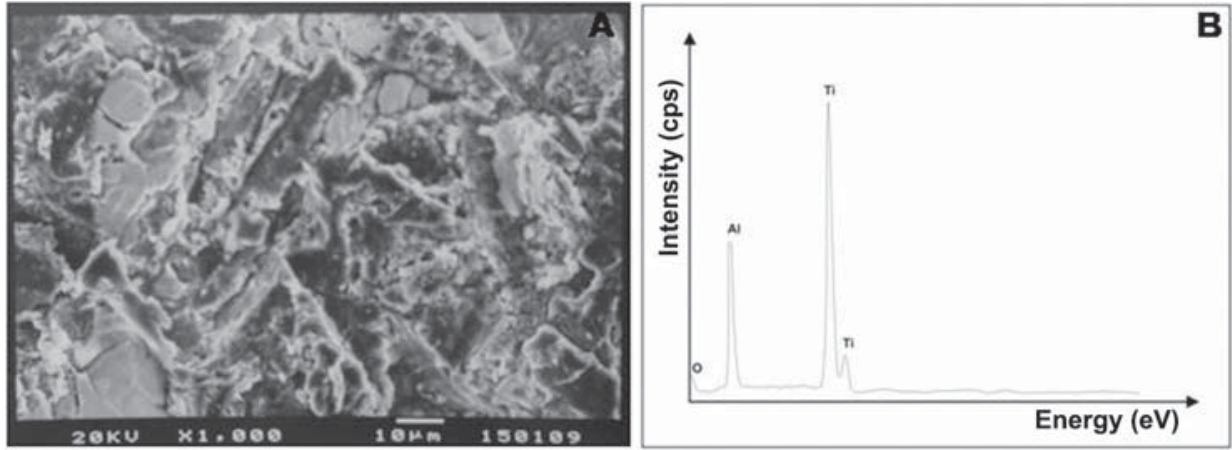

Figure 6- Scanning electron microscopy analysis for cpTi after sandblasting with $250 \mu \mathrm{m} \mathrm{Al}_{2} \mathrm{O}_{3}$

surface were the same in all groups. EDS analysis detected the presence of aluminum and oxide on the sandblasted cpTi surfaces (Figures 5B and 6B).

\section{DISCUSSION}

The present study evaluated the SBS of a resin composite to $\mathrm{cPTi}$ after sandblasting with varying sizes of $\mathrm{Al}_{2} \mathrm{O}_{3}$ particles associated with three metal conditioners or with one surface modification. Overall, the association of metal conditioners and sandblasting increased the SBS in comparison to the values obtained on polished surfaces. The effectiveness of the conditioners on SBS to cpTi airborne-particle-abraded surfaces (50SB and 250SB) and either under the influence of $24 \mathrm{~h}$ water storage or thermal stress ( $\mathrm{TO}$ and $\mathrm{T} 1$ ) was more evident when monomers having phosphoric acid (OP and $\mathrm{TL}$ ) in their composition were used in comparison with those having the carboxylic derivative (MPP). These results are in agreement with those from previous studies ${ }^{36,37}$ that attributed this greater effectiveness to the presence of a hydrophobic group in their compositions. According to Taira, et al. ${ }^{30,31}$ $(1995,1998)$ the pure Ti surface is covered with a layer of titanium oxides that guarantees the resin/ metal bond by its reaction with the monomers derived from carboxylic and phosphoric acids. $\operatorname{Ban}^{3}$ (2003) reported that carboxylic acid (4-AET and 4-META) and phosphoric (MDP) derivatives interact with the oxide film on the surface of basic metals, including titanium, via hydrogen bridges, and with the hydroxyl ions $\left(\mathrm{OH}^{-}\right.$ ) present on the metal surface. Therefore, the first hypothesis, stating that the metal primers provide 
similar increase in SBS, was not validated in the current study. We observed a 1.5 times increase in the resin/Ti bond strength values in comparison with the values observed on a noble alloy. Such increase could be related to the great ability for titanium to oxidate. The micromechanical retention appears to contribute much more than chemical bonding does.

The bond between polymers and metal is not completely justified by these two bonding mechanisms. This conclusion is in agreement with our results, when we compared the polishing group with the 50SB/OD and 250SB/OD groups. The effectiveness of OP and TL may be also attributed to chemical affinity of the phosphoric acid group for the aluminum oxide particles trapped on the metal surface due to sandblasting ${ }^{14,25}$.

Based on the EDS analysis, oxygen and aluminum were only detected on the sandblasted metal surfaces, demonstrating the presence of remaining $\mathrm{Al}_{2} \mathrm{O}_{3}$ particles, as also observed by Ohkubo, et al. ${ }^{23}$ (2000). However, the influence of aluminum on the bonding mechanism is not well known ${ }^{19}$. Cobb, et $a .^{6}$ (2000) described changes in the surface morphology of gold alloys due to the differences in particle sizes and the range in pressure during sandblasting. They also found an increase in the amount of aluminum on the metal surface and the possible chemical affinity of aluminum for functional monomers and phosphoric derivatives. In addition to the micromechanical retention, Kern and Thompson ${ }^{14}$ (1994) reported that the remaining aluminum particles on the metal surface play an important role in the bonding mechanism created by bonding systems with functional monomers.

According to the EDS analysis, it was not possible to observe the presence of remaining compounds from conditioners on the metal surfaces, or even the silicon layer of the $\mathrm{S}$ group. According to Kern and Thompson ${ }^{13}$ (1994) the pyrolytically deposited silicon results in a layer that is invisible to SEM, while Ekstrand, Ruyter and Øysaed ${ }^{10}$ (1988) observed that the presence of polymer molecules on the surfaces of metals can only be detected by infrared spectroscopy. The effects of remaining aluminum particles also hels explain the higher amount of mixed failures in the 250SB group in comparison to those observed in 50SB groups, confirming the greater retention demonstrated by that group.

Thermocycling in a water bath has been used frequently to simulate the intraoral aging effect on resin composite adhesion. However, these simulations vary considerably and any evidence of the number of cycles corresponding to those experienced in vivo was not yet found ${ }^{7,18}$. In the present study, thermocycling had no significant effect on conditioners. Therefore, the metal primers demonstrated reliable bonding without a reduction in bond strength after thermocycling. Thus, the second research hypothesis - establishing that SBS values between resin and metal surface treated with metal primers is not impaired by thermocycling - was validated.

The results of the present study are in agreement with those observed by Özcan and Valandro 26,27 $(2012,2011)$ that observed higher bond strength of resin composite to titanium with phosphoric acid derivatives. According to the authors ${ }^{27}$, the effectiveness of the bond strength can also be influenced by the opaque resin layer applied after the surface treatment and previously the application of aesthetic covering material. The effect of opaquers can be attributed to differences in their chemical composition and form of presentation (powder/liquid or paste) that lead to various consistencies ${ }^{24}$. Özcan and Kumbuloglu ${ }^{24}$ (2009) concluded that although thickness did not affect the bond strength between resin composite to titanium, type of opaquers had a significant effect in the results with higher bond strength for power-liquid form than paste form in both thin and thick application. Moreover, the authors suggested that the degree of water uptake of the opaquers, specifically due the hydrophilic character of the dimethacrylates could influence in bond strength ${ }^{24}$. Since only one opaque resin was tested in the present investigation, further studies are needed in order to evaluate more carefully the influence of this material on the bonding process.

The shear bond strength test was used in this study because shearing forces are the most predominant during chewing ${ }^{4}$. For this reason, this test reproduces more closely what happens to materials in the mouth. On the other hand, it is important to point out that some methods, such as finite analysis and mathematical analysis of stress, demonstrated that nominal bond strength obtained after specimen fracture divided by the cross-sectional area may not represent the true stress generated at the interface ${ }^{33}$. Such a difference between the stress generated during the test and that created during chewing may be attributed to other influencing factors, such as specimen geometry, load type, moment of load application and cynzel position ${ }^{33}$.

The results of this in vitro study suggest that the use of chemical bonding systems combined with a mechanical retention improved the bonding between a resin composite and commercially pure titanium (cpTi). This evidence implies that clinicians may consider the use of techniques that combine chemical bond and mechanical retention when reliable bonding is required between a metal surface and resin composite. Thus, clinicians can be more confident when using composite veneering systems coupled to metals. 


\section{CONCLUSIONS}

According to the results of the current study, it was concluded that an increase in SBS of resin to cpTi may be achieved by associating the mechanical retention provided by sandblasting with $250 \mu \mathrm{m}$ aluminum oxide particles with the chemical bonding created by metal conditioners, mainly by those containing functional monomers derived from phosphoric acid (Cesead II Opaque Primer and Targis link).

\section{ACKNOWLEDGEMENTS}

This investigation was supported by São Paulo Research Foundation - FAPESP Grant 03/02302-2.

\section{REFERENCES}

1- Almilhatti HJ, Giampaolo ET, Vergani CE, Machado AL, Pavarina AC. Shear bond strength of esthetic materials bonded to $\mathrm{Ni}-\mathrm{Cr}$ alloy. J Dent. 2003;31:205-11.

2- Azimian F, Klosa K, Kern M. Evaluation of a new universal primer for ceramics and alloys. J Adhes Dent. 2012;14:275-82.

3- Ban S. Effect of alkaline treatment of pure titanium and its alloys on the bonding strength of dental veneering resins. J Biomed Mater Res. 2003;66:138-45.

4- Behr M, Rosentritt M, Gröger G, Handel G. Adhesive bond of veneering composite on various metal surfaces using silicoating, titanium-coating or functional monomers. J Dent. 2003;31:33-42. 5- Chang JC, Koh SH, Powers JM, Duong JH. Tensile bond strengths of composites to a gold-palladium alloy after thermal cycling. ] Prosthet Dent. 2002;87:271-6.

6- Cobb DS, Vargas MA, Fridrich TA, Bouschlicher MR. Metal surface treatment: characterization and effect on composite-to-metal bond strength. Oper Dent. 2000;25:427-33.

7- Crim GA, Garcia-Godoy F. Microleakage: the effect of storage and cycling duration. J Prosthet Dent. 1987;57:574-6.

8- Crim GA, Mattingly SL. Evaluation of two methods for assessing marginal leakage. J Prosthet Dent. 1981;45:160-3.

9- Di Francescantonio M, Oliveira MT, Daroz LG, Henriques GE, Giannini M. Adhesive bonding of resin cements to cast titanium with adhesive primers. Braz Dent J. 2012;23:218-22.

10- Ekstrand K, Ruyter IE, Øysaed H. Adhesion to titanium of methacrylate-based polymer materials. Dent Mater. 1988;4:111-5. 11- Fonseca RG, Almeida JG, Haneda IG, Adabo GL. Effect of metal primers on bond strength of resin cements to base metals. J Prosthet Dent. 2009;101:262-8.

12- Gale MS, Darvell BW. Thermal cycling procedure for laboratory testing of dental restorations. J Dent. 1999;27:89-99.

13- Kern M, Thompson VP. Effects of sandblasting and silicacoating procedures on pure titanium. J Dent. 1994;22:300-6.

14- Kern M, Thompson VP. Influence of prolonged thermal cycling and water storage on the bond strength of composite to $\mathrm{NiCr}$ alloy. Dent Mater. 1994;9:19-25.

15- Kern M, Thompson VP. Durability of resin bonds to a cobaltchromium alloy. J Dent. 1995;23:47-54.

16- Koizumi H, Ishii T, Naito K, Yoneyama T, Tanoue N, Matsumura $\mathrm{H}$. Effects of triazine dithione and hydrophobic phosphate monomers on bonding to Ag-Pd-Cu-Au alloy and titanium with a methacrylic resin-based luting agent. J Adhes Dent. 2010;12:21522.

17- Koizumi $H$, Naito $K$, Ishii T, Yamashita M, Yoneyama T, Matsumura $\mathrm{H}$. Adhesive bonding of Ti-6Al-7Nb alloy and component metals with acidic primers and tri-n-butylborane initiated resin. J Adhes Dent. 2012;14:283-92.
18- Lakatos S, Romînu M, Negrutiu M, Florita Z. The microleakage between alloy and polymeric materials in veneer crowns. Quintessence Int. 2003;34:295-300.

19- Lim BS, Heo SM, Lee YK, Kim CW. Shear bond strength between titanium alloys and composite resin: sandblasting versus fluoride-gel treatment. J Biomed Mater Res. 2003;64:38-43.

20- Matinlinna JP, Lassila LVJ, Vallittu PK. Evaluation of five dental silanes on bonding a luting cements onto silica-coated titanium. J Dent. 2006;34:721-6.

21- Matsumura $\mathrm{H}$, Yoneyama $\mathrm{T}$, Shimoe S. Veneering technique for a Ti-6Al-7Nb framework used in a resin-bonded fixed partial denture with a highly filled indirect composite. J Prosthet Dent. 2002;88:636-9.

22- Michailesco PM, Marciano J, Grieve AR, Abadie MJ. An in vivo recording of variations in oral temperature during meals: a pilot study. J Prosthet Dent. 1995;73:214-8.

23- Ohkubo C, Watanabe I, Hosoi T, Okabe T. Shear bond strengths of polymethyl methacrylate to cast titanium and cobaltchromium frameworks using five metal primers. J Prosthet Dent. 2000;83:50-7.

24- Özcan M, Kumbuloglu O. Effect of composition, viscosity and thickness of the opaquer on the adhesion of resin composite to titanium. Dent Mater. 2009;25:1248-55.

25- Özcan M, Pfeiffer P, Nergiz I. A brief history and current status of metal- and ceramic surface-conditioning concepts for resin bonding in dentistry. Quintessence Int. 1998;29:713-24.

26- Özcan M, Valandro LF. Effect of silane coupling agents and alloy primers on adhesion to titanium. Minerva Stomatol. 2011;60:427-34.

27- Özcan M, Valandro LF. Bond strength of two resin cements to titanium after different surface conditioning methods. Gen Dent. 2012;60:e6-e12.

28- Petridis H, Garefis P, Hirayama H, Kafantaris NM, Koidis PT. Bonding indirect resin composites to metal: Part 1. Comparison of shear bond strengths between different metal-resin bonding systems and a metal-ceramic system. Int J Prosthodont. 2003;16:635-9.

29- Shimizu H, Kutz KS, Tachii Y, Takahashi Y. Use of metal conditioners to improve bond strengths of autopolymerizing denture base resin to cast Ti-6Al-7Nb and Co-Cr. J Dent. 2006; 34:117-22.

30- Taira Y, Matsumura H, Yoshida K, Tanaka T, Atsuta M. Adhesive bonding of titanium with a methacrylate-phosphate primer and self-curing adhesive resins. J Oral Rehabil. 1995;22:409-12.

31- Taira Y, Matsumura H, Yoshida K, Tanaka T, Atsuta M. Influence of surface oxidation of titanium on adhesion. J Dent. 1998;26:69-73.

32- Tsuchimoto Y, Yoshida Y, Takeuchi M, Mine A, Yatani H, Tagawa $Y$, et al. Effect of surface pre-treatment on durability of resin-based cements bonded to titanium. Dent Mater. 2006;22:545-52.

33- Van Noort R, Noroozi S, Howard IC, Cardew G. A critique of bond strength measurements. J Dent. 1989;17:61-7.

34- Vojvodic D, Jerolimov V, Celebic A, Catovic A. Bond strengths of silicoated and acrylic resin bonding systems to metal. J Prosthet Dent. 1999;81:1-6.

35- Vojvodic D, Predanic-Gasparac, Brkic H, Celebic A. The bond strength of polymers and metal surfaces using the "silicoater" technique. J Oral Rehabil. 1995;22:493-9.

36- Yanagida $H$, Matsumura $H$, Atsuta $M$. Bonding of prosthetic composite material to $\mathrm{Ti}-6 \mathrm{Al}-7 \mathrm{Nb}$ alloy with eight metal conditioners and surface modification technique. Am J Dent. 2001;14:291-4.

37- Yanagida H, Matsumura H, Taira $Y$, Atsuta M, Shimoe S. Adhesive bonding of composite material to cast titanium with varying surface preparations. J Oral Rehabil. 2002;29:121-6. 38- Yoshida K, Kamada K, Atsuta M. Adhesive primers for bonding cobalt-chromium alloy to resin. J Oral Rehabil. 1999;26:475-8. 39- Yoshida K, Taira Y, Matsumura H, Atsuta M. Effect of adhesive metal primers on bonding a prosthetic composite resin to metals. J Prosthet Dent. 1993;69:357-62. 